\title{
Pitfalls in Pacemaker Implant for Hypersensitivity of the Carotid Sinus
}

\author{
Marcos Benchimol $^{1 *}$, llana Benchimol ${ }^{2}$ and Ricardo de Oliveira Souza ${ }^{3}$ \\ ${ }^{1}$ Federal University of Rio de Janeiro, Brazil \\ ¿Universidade Estácio de Sá, Brazil \\ ${ }^{3}$ Federal University of the State of Rio de Janeiro, Brazil
}

*Corresponding author: Marcos Benchimol, Federal University of Rio de Janeiro, Rua Redentor, Rio de Janeiro, RJ, Brazil, Zip code: 22421030; E-mail: marcosbenchi@hotmail.com

Received: 28 Jan, 2019 | Accepted: 01 Mar, 2019 | Published: 08 Mar, 2019

Citation: Benchimol M, Benchimol I, de Oliveira Souza R (2019) Pitfalls in Pacemaker Implant for Hypersensitivity of the Carotid Sinus. J Clin Case Stu 4(1): dx.doi.org/10.16966/2471-4925.182

Copyright: @ 2019 Benchimol M, et al. This is an open-access article distributed under the terms of the Creative Commons Attribution License, which permits unrestricted use, distribution, and reproduction in any medium, provided the original author and source are credited.

\section{Introduction}

Syncope is the cause of $3 \%$ and $1 \%$ of emergency and hospital admissions, respectively [1-4]. It is the final common pathway of a host of different pathophysiological mechanisms [5]. Accurate diagnosis of the mechanism of syncope is essential for adequate management and prognosis in individual cases.

Prior to the introduction of the head up tilt table test (HUTT) in clinical practice, most cases of syncope remained undiagnosed. The routine use of the HUTT has shown that reflex syncope comprises the most frequent mechanism underpinning those cases previously diagnosed as "syncope of undetermined origin" [6,7].

Reflex syncope is currently classified as (i) vasovagal (the common faint), (ii) situational (cough, micturition, laugh, defecation, and (iii) carotid sinus syndrome (CSS) [8]. CSS is said to be present when a loss of consciousness is elicited in response to accidental mechanical manipulation of the carotid sinus region. It can be reproduced in the lab through carotid sinus massage (CSM) [9]. Carotid sinus hypersensitivity (CSH) represents a ventricular pause $>3$ seconds and/or a fall in systolic blood pressure $>50 \mathrm{mmHg}$ after carotid sinus massage. The CSS is a rare condition, accounting for only $1 \%$ of patients with syncope in most clinical series [10]. CSS is most common in elderly men [11]. It also constitutes one important mechanism underlying cases of unexplained falls in the elderly [12].

About CSM there is strong consensus that the diagnosis of CSS requires both the reproduction of spontaneous symptoms during CSM and clinical features of spontaneous syncope compatible with a reflex mechanism.

Syncope in patients with carotid sinus hypersensitivity almost always occurs in the standing or sitting position [13].

From a hemodynamic perspective, CSS can be (i) cardioinhibitory (asystole lasting $>3$ seconds in response to CSM], (ii) vasodepressor (drop of systolic pressure $>50 \mathrm{mmHg}$ in response to CSM), or (iii) mixed, when asystole and hypotension co-occur in the same patient $[10,14]$. European Society of Cardiology, ESC, Task Force on Syncope recommends CSM in individuals over 40 years in the investigation of unexplained syncope [15]. CSM requires massage performed for 10 seconds on both sides in both supine and upright positions [15]. There is little agreement among different authors on the relative prevalence of these mechanisms. Differences in methods of blood pressure assessment may explain some of these discrepancies. The following case illustrates how a misinterpretation of the hemodynamic response to carotid sinus massage may delay the correct diagnosis and perpetuate the occurrence of syncope.

\section{Case Description}

Informed consented was given by the patient to publish his case report.

A 71-year-old man reported several episodes of fainting when standing over the few weeks before his first consultation. He worked as lawyer. The loss of consciousness episodes had no relation with head movements or neck manipulation. In one such episode, he sustained a severe facial trauma, indicating that at least some of his faints were not preceded by warning signs. His cardiovascular and neurologic exams were normal, as were his blood tests, electrocardiogram (EKG), Doppler echocardiogram, electroencephalogram, 24-hour Holter monitoring, head CT, and duplex scans of the vertebral and carotid arteries. He did not develop hypotension on standing, nor was he taking drugs that might explain his falls. His premorbid history did not provide clues for the cause of his faints either. To further investigate the etiology of his syncope, the patient underwent a HUTT preceded by CSM as detailed in a previous article [16]. Briefly, the tilt test table was equipped with a $\mathrm{TEB}^{\star}$ system for continuous EKG monitoring and support for the feet, allowing $60-80^{\circ} \mathrm{C}$ inclinations. Blood pressure was measured with an oscillometric device and the measures were confirmed by sphygmomanometer every two minutes or less in case of symptoms. Beginning with the right side, CSM was 


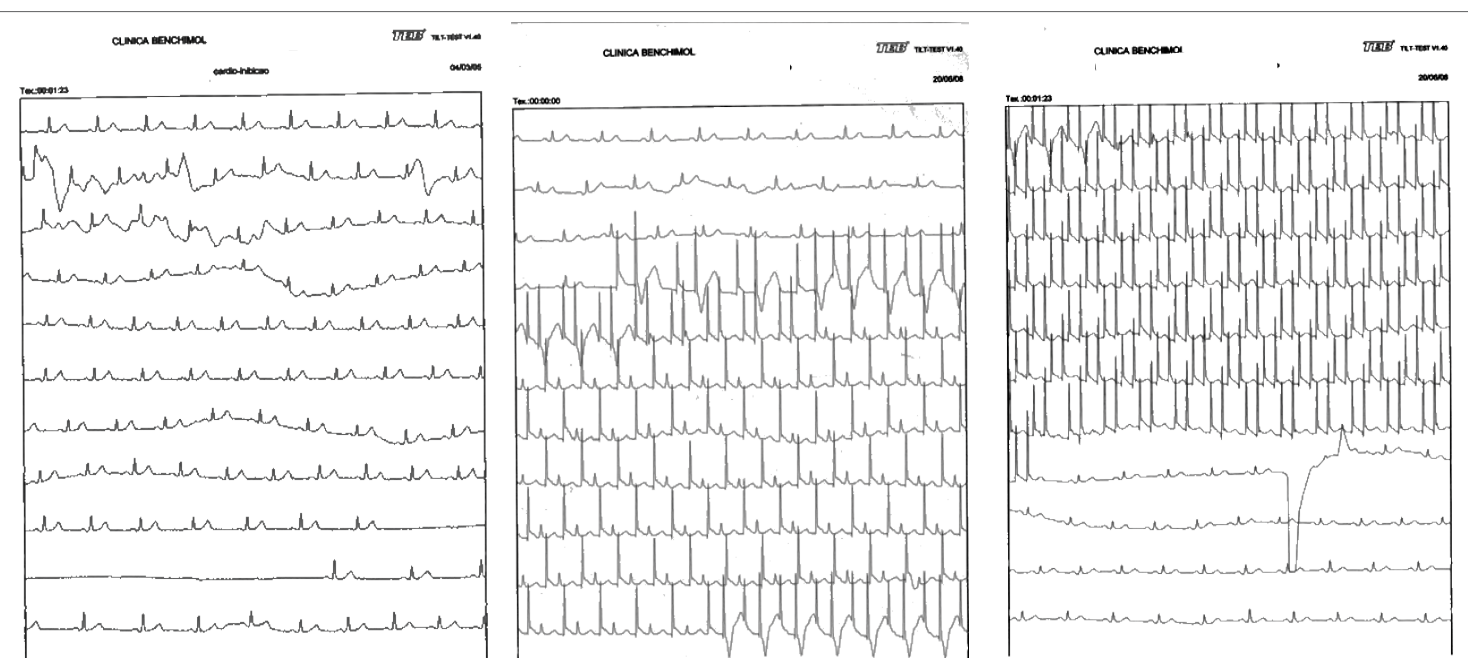

Figure 1A: CSM before pacing showing cardioinhibitory pattern (asystole lasting 7 seconds). 1B: Despite pacemaker activation during right CSM, there was a fall in systolic pressure with convulsive syncope, revealing the existence of a hitherto undisclosed vasodepressor component. 1C: Return to sinus rhythm followed by hemodynamic stabilization and recovery of consciousness.

manually applied during 5 seconds to each carotid sinus at a time with the patient in the supine position at zero degree. After one minute of rest, the table was inclined at $60^{\circ} \mathrm{C}$ and the procedure was repeated. The HUTT consisted of two stages, namely, (i) a "passive" stage, and (ii) a pharmacologically sensitized stage, which consisted in administering $1.25 \mathrm{mg}$ of isosorbide dinitrate by sublingual route. Each phase lasted 25 minutes or less, in case of the emergence of pre-syncopal symptoms.

There was a positive cardioinhibitory response to right CSM at $60^{\circ} \mathrm{C}$ with a systolic pause of 7 seconds. Left CSM and the HUTT were negative. Based on these findings, the patient received a diagnosis of CSS, cardioinhibitory subtype. A DDI bicameral pacemaker with ratedrop response function was implanted following the guidelines of the Brazilian Society of Cardiology [17].

In spite of the procedure, the syncope episodes persisted unchanged, with a resulting severe limitation of the patient's activities of daily living, a follow-up exam was performed. This time, however, right CSM elicited a systolic drop of $80 \mathrm{mmHg}$. Despite prompt activation of the pacemaker and increase in heart rate to $100 \mathrm{bpm}$, the patient lost consciousness and developed convulsive movements. Left CSM and the HUTT were again negative (Figure 1).

\section{Discussion and Conclusion}

In our patient, the fainting spells persisted despite pacemaker activation. Follow-up CSM in the setting of the HUTT revealed that persistence of syncope was due to a hitherto not apparent vasodepressor component. He thus received a diagnosis of CSS, mixed subtype. Indeed, the vasodepressor component was probably present by the time when the first CSM was performed; however, the strong cardioinhibitory response and the technique of gauging the arterial pressure may have prevented its expression, especially if the drop in systolic pressure was quick and brief as it often is [18]. Since hypotension following asystole may result from either vasodepression or bradycardia, in cases of doubtful diagnosis, the vasodepressor component may be disclosed by repeating the CSM after blockage of cardioinhibition by venous administration of atropine or by pacing the patient [19].

It should be noted that $\mathrm{CSH}$ may be a quite common finding. Kerr found CSH in 23 out of 80 (35\%) asymptomatic individuals older than
65 years old [20] so clinical judgment must be used before attributing the cause of syncope to CSH. This points that place a cardiac pacemaker merely by a CSH finding should not be appropriated. It is relevant to mention that this patient had CSS recurrence even though his HUTT was negative. Gaggioli [21] observed that individuals with CSH and positive HUTT were more likely to have CSS recurrence.

According to Wieling [22], a new classification of CSH should be undertaken because the 3 -seconds criteria [10] is too loose as the cerebral anoxia reserve time is about $5-8$ seconds $[23,24]$ as long as the frequent finding of the duration of the asystole [20].

Patients with a vasodepressor CSS can be managed with withholding pharmacological vasodilators, such as angiotensin-converting enzyme inhibitors, calcium antagonists and long-acting nitrates, should be considered because all these agents prolong the recovery of arterial pressure [25].

Duration of 6 seconds to define clinically significant asystole is also supported by recent data obtained in a large unselected community sample of elderly people (272 participants, age 65-99 years old). In this sample the $95 \%$ cut-off for cardioinhibition was 7 seconds of asystole in the supine position and 5.5 seconds in the upright position; in addition, all patients with cardiac standstills of $>7.0$ seconds and $>5.5$ seconds in these positions, respectively, were symptomatic [20].

In order to detect the abrupt drop of blood pressure with a manually inflated arm cuff, it should be done at each 10 seconds pending of the heart rate, which is almost impossible. Thus, the ideal method would be an invasive method or by plethysmography (Finapres ${ }^{\oplus}$ NOVA). Many of the apparent cardioinhibitory type have indeed the mixed form, so the vasodepressor component should be excluded by pacing, which is not clinically feasible in most patients, or by previous administration of $1 \mathrm{mg}$ of Atropine. If a drop of $50 \mathrm{mmHg}$ of the systolic blood pressure is observed while bradycardia has been corrected, the possible benefits of pacing would be blunt as it was the case.

\section{References}

1. Sun BC, Emond JA, Camargo CA Jr. (2004) Characteristics and admission patterns of patients presenting with syncope to U.S. emergency departments, 1992-2000. Acad Emerg Med 11: 1029-1034. 
2. Kapoor WN (1990) Evaluation and outcome of patients with syncope. Medicine (Baltimore) 69: 160-175.

3. Manolis AS, Linzer M, Salem D, Estes NA $3^{\text {rd }}$ (1990) Syncope: current diagnostic evaluation and management. Ann Intern Med 112: 850-863.

4. Costantino G, Sun BC, Barbic F, Bossi I, Casazza G, et al. (2016) Syncope clinical management in the emergency department: a consensus from the first international workshop on syncope risk stratification in the emergency department. Eur Heart J 37: 14931498.

5. Arthur W, Kaye GC (2000) The pathophysiology of common causes of syncope. Postgrad Med J 76: 750-753.

6. Kenny RA, Ingram A, Bayliss J, Sutton R (1986) Head-up tilt: a useful test for investigating unexplained syncope. Lancet 1: 1352-1355.

7. Benditt DG, Ferguson DW, Grubb BP, Kapoor WN, Kugler J, et al. (1996) Tilt table testing for assessing syncope. American College of Cardiology. J Am Coll Cardiol 28: 263-275.

8. Kapoor WN (2000) Syncope. N Engl J Med 343: 1856-1862.

9. Kenny RA, O'Shea D, Parry SW (2000) The Newcastle protocols for head-up tilt table testing in the diagnosis of vasovagal syncope, carotid sinus hypersensitivity, and related disorders. Heart 83: 564-569.

10. Krediet $\mathrm{CT}$, Parry SW, Jardine DL, Benditt DG, Brignole M, et al. (2011) The history of diagnosing carotid sinus hypersensitivity: why are the current criteria too sensitive? Europace 13: 14-22.

11. Smebye KL, Granum S, Wyller TB, Mellingsæter M (2014) Medical findings in an interdisciplinary geriatric outpatient clinic specialising in falls. Tidsskr Nor Laegeforen 134: 705-709.

12. Richardson DA, Bexton RS, Shaw FE, Kenny RA (1997) Prevalence of cardioinhibitory carotid sinus hypersensitivity in patients 50 years or over presenting to the accident and emergency department with "unexplained" or "recurrent" falls. Pacing Clin Electrophysiol 20: 820-823.

13. Thomas JE (1969) Hyperactive carotid sinus reflex and carotid sinus syncope. Mayo Clin Proc 44: 127-139.

14. Weiss S, Baker JP (1933) The carotid sinus reflex in health and disease. Its role in the causation of fainting and convulsions. Medicine 12: 297-354.
15. Brignole M, Moya A, de Lange FJ, Deharo JC, Elliott PM, et al. (2018) 2018 ESC Guidelines for the diagnosis and management of syncope. Eur Heart J 39: 1883-1948.

16. Benchimol M, Oliveira-Souza R (2008) Diagnostic relevance of the carotid sinus massage during a head up tilt table test (HUTT). Arq Bras Cardiol 90: 264-267.

17. Filho MM, Zimerman LI, Lorga AM, Vasconcelos JTM, Rassi A Jr. (2007) Guidelines for Implantable Electronic Cardiac Devices of the Brazilian Society of Cardiology. Arq Bras Cardiol 89: e210-e238.

18. Barlow ED, Howarth S (1953) Effects on blood pressure of ventricular asystole during Stokes-Adams attacks and acetylcholine injections. Br Med J 2: 863-864.

19. Stryjer D, Friedensohn A, Schlesinger Z (1982) Carotid sinus hypersensitivity: diagnosis of vasodepressor type in the presence of cardioinhibitory type. Pacing Clin Electrophysiol 5: 793-800.

20. Kerr SR, Pearce MS, Brayne C, Davis RJ, Kenny RA (2006) Carotid sinus hypersensitivity in asymptomatic older persons: implications for diagnosis of syncope and falls. Arch Intern Med 166: 515-520.

21. Gaggioli G, Brignole M, Menozzi C, Devoto G, Oddone D, et al. (1995) A positive response to head-up tilt testing predicts syncopal recurrence in carotid sinus syndrome patients with permanent pacemakers. Am J Cardiol 76: 720-722.

22. Wieling W, Krediet CT, Solari D, de Lange FJ, van Dijk N, et al. (2013) At the heart of the arterial baroreflex: a physiological basis for a new classification of carotid sinus hypersensitivity. J Intern Med 273: 345-358.

23. Puggioni E, Guiducci $\mathrm{V}$, Brignole $\mathrm{M}$, Menozzi $\mathrm{C}$, Oddone $\mathrm{D}$, et al. (2002) Results and complications of the carotid sinus massage performed according to the "method of symptoms". Am J Cardiol 89: 599-601.

24. Brignole M, Menozzi C, Gaggioli G, Musso G, Foglia-Manzillo G, et al. (1998) Effects of long-term vasodilator therapy in patients with carotid sinus hypersensitivity. Am Heart J 136: 264-268.

25. Solari D, Tesi F, Unterhuber M, Gaggioli G, Ungar A, et al. (2017) Stop vasodepressor drugs in reflex syncope: a randomised controlled trial. Heart 103: 449-455. 